\title{
A EDUCAÇÃO BÁSICA NA AMAZÔNIA E SEUS INDICADORES DE QUALIDADE SOCIAL: CONTRADIÇÕES E DESAFIOS PARA O ENSINO MÉDIO NO AMAPÁ*
}

\author{
THE BASIC EDUCATION IN THE AMAZON AND ITS \\ INDICATORS OF SOCIAL QUALITY: CONTRADICTIONS AND \\ CHALLENGES FOR MIDDLE SCHOOL IN AMAPÁ
}

\author{
João Paulo da Conceição Alves* \\ Quésia de Oliveira Cardoso**t
}

\begin{abstract}
RESUMO: O Ensino Médio corresponde a um nível de ensino propício à construção da identidade, projetos de vida e trajetória profissional dos sujeitos. O objetivo deste trabalho é analisar o Ensino Médio no estado do Amapá, considerando a sua qualidade social, tendo como base os indicadores educacionais oficiais. Utilizamos 0 levantamento bibliográfico para analisar o ensino médio público brasileiro, suas características e a seus indicadores de qualidade; além disso, utilizaremos dados do INEP sobre os indicadores educacionais de rendimento do Ensino Médio amapaense em 2015, para o desenvolvimento de análises correlacionadas aos índices de Desenvolvimento Humano dos Municípios - IDHM, índice de GINI e o índice de Pobreza. Nossas análises evidenciaram que o Ensino Médio no Amapá, apresentou índices negativos em relação à zona urbana, pois as taxas de Reprovação e Abandono no ano de 2015 foram elevadas. Diferente da zona rural que demonstrou dados positivos referentes ao fluxo no Ensino Médio, no entanto com baixos indicadores de qualidade social. Os maiores centros urbanos do estado, mesmo com a melhor estrutura, não apresentaram os melhores índices de ensino. De forma geral, os dados relacionados ao ensino apresentam disparidades em relação aos índices de desenvolvimento social e humano.
\end{abstract}

Palavras-chave: Ensino Médio; Indicadores educacionais; Qualidade social; Amapá.

\footnotetext{
"Esse artigo constitui-se parte dos resultados do projeto de pesquisa intitulado: Análises e mediações sobre as formas de realização, a qualidade social e a política de formação do Ensino Médio no estado do Amapá, em desenvolvimento na Universidade Federal do Amapá (UNIFAP/DPq).

** Doutorado em Educação pela Universidade Federal do Pará (UFPA). Docente da Universidade Federal do Amapá (Unifap) e do Programa de Pós-Graduação em Educação e Cultura da UFPA. É associado à Associação Nacional de Pós-Graduação em Educação (ANPED), à Sociedade Brasileira para o Progresso da Ciência (SBPC) e à Associação Nacional de Política e Administração da Educação (ANPAE), da qual é coordenador da sua seção no estado do Amapá. Contato: jpaulochee@gmail.com

*** Graduação em Pedagogia pela Universidade Federal do Amapá (Unifap). Membro do grupo de pesquisas Educação, Trabalho e Formação Humana (GEFOR/UNIFAP). Docente na educação básica. Contato: quesiacardoso10@gmail.com
} 
ABSTRACT: The High School corresponds to a level of education conducive to the construction of the identity, life projects and professional trajectory of the subjects. The objective of this study is to analyze the High School in the state of Amapá, considering its social quality, based on official educational indicators. We used the bibliographic survey to analyze the Brazilian public secondary education, its characteristics and its quality indicators; In addition, we will use INEP data on educational indicators of high school income in amapaense in 2015, for the development of analyzes correlated to the Human Development Indexes of Municipalities - IDHM, GINI index and the Poverty index. Our analyzes showed that the high school in Amapá had negative indices in relation to the urban zone, since the rates of Reprobation and Abandonment in 2015 were high. Different from the rural area that showed positive data regarding the flow in High School, however with low indicators of social quality. The largest urban centers in the state, even with the best structure, did not have the best levels of education. In general, data related to education show differences in relation to social and human development indexes.

Keywords: High School; Educational indicators; Social quality; Amapá.

\section{INTRODUÇÃO}

A importância deste trabalho parte da verificação da ausência de estudos que tome o Ensino Médio como base, mesmo se tratando de um nível de ensino com baixos índices de desenvolvimento educacional no Brasil, e particularmente no estado do Amapá.

Este trabalho tem por objetivo central analisar a qualidade social do Ensino Médio da rede pública do estado do Amapá nas zonas rural e urbana mediante análises e correlações de indicadores educacionais/sociais. Dessa forma especificamente, identificamos a realidade do Ensino Médio no estado do Amapá segundo os índices de rendimento escolar; analisamos os índices de desenvolvimento humano do estado e sua relação com os resultados do Ensino Médio amapaense.

Este trabalho foi dividido em duas etapas. Na primeira adotamos como procedimento de pesquisa o levantamento bibliográfico objetivando analisar algumas características do Ensino Médio público no estado do Amapá. Utilizamos como referências centrais Alves, Araújo, Rodrigues (2015), Ciavatta, Ramos (2011) e Kuenzer (2000). 
A segunda etapa tem como objetivo levantar os indicadores educacionais de rendimento Escolar do ano de $2015^{1}$ seguidos pela complementação de dados a partir dos índices relacionadas ao índice de Desenvolvimento Humano dos Municípios - IDHM, ${ }^{2}$ índice de $\mathrm{GINI}^{3}$ e o Índice de Pobreza. ${ }^{4}$

Esta pesquisa foi desenvolvida no estado do Amapá, considerando a análise de indicadores educacionais nas suas zonas rural e urbana, na rede pública de ensino. Os dados foram obtidos no sítio do Instituto Nacional de Estudos e Pesquisas Educacionais Anísio Teixeira (INEP), e utilizamos uma abordagem quantitativa e qualitativa para explicitação e análise dos dados.

Do ponto de vista metodológico, não há contradição, assim como não há continuidade, entre investigação quantitativa e qualitativa. (...) $\mathrm{A}$ primeira tem como campo de práticas e objetivos trazer à luz dados, indicadores e tendências observáveis. Deve ser utilizada para abarcar, do ponto de vista social, grandes aglomerados de dados, de conjuntos demográficos, por exemplo, classificando-os e tornando os inteligíveis através de variáveis. A segunda adequa-se a aprofundar a complexidade de fenômenos, fatos e processos particulares e específicos de grupos mais ou menos delimitados em extensão e capazes de serem abrangidos intensamente. (MINAYO; SANCHES, 1993, p. 247)

Mediante os dados coletados, analisamos alguns indicadores educacionais do ensino médio (aprovação, reprovação, abandono e distorção idade-série e nível sócio- econômico), favorecendo uma análise comparativa

\footnotetext{
1 Optamos pela analise do Ensino Médio no ano de 2015 pela atualidade dos dados, sendo 0 último ano com dados disponíveis no sítio do INEP no período da realização da pesquisa sobre a qualidade social do Ensino Médio no estado do Amapá.

${ }^{2} \mathrm{O}$ Índice de Desenvolvimento Humano Municipal (IDHM) é uma medida composta de indicadores de três dimensões do desenvolvimento humano: longevidade, educação e renda. 0 índice varia de 0 a 1 . Quanto mais próximo de 1 , maior o desenvolvimento humano.

${ }^{3}$ O coeficiente de Gini (ou índice de Gini) é um cálculo usado para medir a desigualdade social, desenvolvido pelo estatístico italiano Corrado Gini, em 1912. Apresenta dados entre o número 0 e o número 1, onde zero corresponde a uma completa igualdade na renda (onde todos detêm a mesma renda per capita) e um que corresponde a uma completa desigualdade entre as rendas (onde um indivíduo, ou uma pequena parcela de uma população, detêm toda a renda e os demais nada têm). Gini mede o coeficiente através de pontos percentuais (que é igual ao coeficiente multiplicado por 100).

${ }_{4} \mathrm{O}$ Índice de Pobreza Humana (IPH) é um indicador criado pela ONU em 1997 para medir a pobreza humana e que utiliza no seu cálculo três dimensões base: -Longevidade: representada pela percentagem de pessoas que morrem antes dos 40 anos; -Conhecimento: representado pela percentagem de adultos analfabetos; -Nível de vida: representado pela percentagem de pessoas com acesso a serviços de saúde, percentagem de pessoas com acesso a água potável e percentagem de crianças subnutridas.
} 
dessa etapa. Como critérios utilizados para a filtragem e análise dos dados, foram selecionados somente os dados das escolas estaduais e públicas nas zonas rural e urbana.

As análises desconsiderarão os dados de aprovação, reprovação ou abandono nos municípios amapaenses que apresentarem percentuais equivalentes a $0 \%$ ou $100 \%$, pois, o registro desses dados pode nos revelar eventuais imprecisões, disparidades, ou mesmo descontextualizar a realidade das escolas, sugerindo-nos, portanto, equívocos nos seus registros.

\section{A DUALIDADE DO ENSINO MÉDIO E SUA QUALIDADE SOCIAL}

Historicamente, o Ensino Médio (nas suas diversas formas e nomenclaturas) apresentou caráter dual, sob um recorte de classe: a educação de qualidade nunca foi destinada prioritariamente às classes desfavorecidas. Nesse sentido, a sociedade impõe a necessidade de um ensino distinto e "adequado" à realidade econômica e social de cada classe.

A década de 1990, por exemplo, caracteriza-se como período que manifesta fortemente o Ensino Médio de caráter dual e, contraditoriamente a emersão de reivindicações em defesa de uma escola pública de qualidade. 0 Ensino Médio foi um dos espaços dessas transformações principalmente no que se refere ao seu caráter formativo: destacamos nesse caso a preparação das classes dirigentes para o ingresso no ensino superior, e para a classe trabalhadora adentrar as formações técnicas aligeiradas.

Em 1996 com a aprovação da Lei de Diretrizes e Bases da Educação ocorreram transformações com destaque às mudanças no perfil do ensino médio público, repercutindo na sua qualidade. Em 1998, por exemplo, mediante a aprovação do decreto $n^{\circ} 2.494 / 1998$, representou na prática o aprofundamento da separação entre o ensino geral e profissionalizante. Se pautou uma educação de lógica imediata e com fins de mercado: toma-se como fundamento da análise a qual aponta que os filhos da classe trabalhadora não viam condições de prosseguir na trajetória escolar devido a necessidade de subsistência e a necessidade de uma formação rápida. 


\begin{abstract}
Vale registrar o fato de a educação profissional, nessa reforma, ser reiterada como o ensino destinado à classe trabalhadora e alternativo ao nível superior. A ideologia da empregabilidade sustentou a responsabilização dos próprios trabalhadores pelo desemprego, sendo que a qualificação e a requalificação profissional foram considerados meios de acesso a setores ocupacionais, prevalecendo, para a maioria dos trabalhadores, a periferia da produção, esfera em que predomina tanto a lógica taylorista-fordista quanto a precarização do trabalho. (CIAVATTA, 2011, p.30).
\end{abstract}

Diante disso, ao analisarmos o conceito de qualidade, observamos sob um viés social e, portanto, de forma distinta frente ao recorte de classe na sociedade e na escola pública. Trata-se de entender o conceito de qualidade sob uma dimensão social, portanto, pensada para a sociedade principalmente aos sujeitos em contextos sociais de exclusão.

Dourado, Oliveira (2007) e Santos (2016), consideram as dimensões intra e extraescolares que afetam as condições de ensino e aprendizagem. A dimensão intraescolar compreende: as condições de oferta do ensino (plano do sistema); a gestão e organização do trabalho escolar (plano da escola); a formação, profissionalização e ação pedagógica do professor (plano do professor) e; as condições de acesso, permanência e desempenho escolar (plano do aluno). Enquanto a dimensão extraescolar corresponde aos fatores econômicos, socioculturais e às obrigações do Estado no provimento público da educação e na viabilização de condições de formação e valorização da carreira docente.

\begin{abstract}
Antes de colocar a questão dos parâmetros da qualidade - isto é, de como medir a qualidade - essa abordagem política do tema coloca em questão a própria noção de qualidade, relacionando-a ao tipo de escola ou de universidade que queremos, enfim, ao tipo de sociedade que queremos. $\mathrm{E}$ aponta a necessidade de se trabalhar primeiro 0 que condiciona a qualidade. Não tratar a qualidade como uma questão separada dos seus condicionantes. A qualidade na educação é o resultado das condições que oferecemos a ela. Para obtermos outra qualidade precisamos mexer primeiramente nessas condições (GADOTTI, 2013, p. 05).
\end{abstract}

Partimos da compreensão que uma das alternativas viáveis para a realização do Ensino Médio com qualidade social pauta-se numa escola integradora de conhecimentos técnicos e propedêuticos; um ensino de qualidade para àqueles que historicamente foram excluídos dessa etapa de ensino. Trata-se de uma educação que reflita as necessidades reais dos 
alunos. Referimo-nos a uma questão política e filosófica, muito além de sua mera institucionalização, ou seja, depende "[...] muito mais do posicionamento que a instituição e o profissional da educação assumem frente à realidade do que aos procedimentos didáticos que são pautados pela organização do curso e que serão utilizados pelos docentes" (ARAUJO; RODRIGUES, 2010, p. 18).

Consideramos o Ensino Médio como etapa de formação fundamental para a definição da vida profissional e social dos sujeitos, e a desintegração deste nível de ensino, constitui-se na sua dualidade e portanto, em conhecimentos fragmentados para os mais pobres. Assim, este nível de ensino é marcado por uma série de problemas relacionados à dualidade ${ }^{5}$ no ensino, no que se refere a uma educação para as classes dirigentes e outra para àquelas socialmente desfavorecidas.

A dualidade no ensino aponta o Ensino Médio dividido em duas direções distintas, mediadas pelo recorte de classe: uma que leva a continuação da obtenção de conhecimentos superiores, a outra, ao mercado de trabalho. A escola reflete o modelo do sistema vigente, preparando muitos para serem reprodutores desta divisão, sem priorizar a formação de sujeitos para a transformação da realidade em que estão inseridos.

No caso do ensino médio e da educação profissional, essa visão dual
ou fragmentada expressa-se, historicamente, desde a Colônia, pela
reprodução das relações de desigualdade entre as classes sociais, na
separação entre a educação geral, como preparação para os estudos
superiores, e a preparação imediata para o mercado de trabalho,
funcional às exigências produtivas (CIAVATTA; RAMOS, 2011, p. 28).

Neste caso, pensar a qualidade social na escola pública significa transformar positivamente a vida dos sujeitos para atender e melhorar determinada realidade.

Observada pela função social, a educação de qualidade se realiza na medida em que logre preparar o indivíduo para o exercício da ética profissional e da cidadania. Supõe, ainda, educá-lo para compreender e ter acesso a todas as manifestações da cultura humana; do ângulo puramente pragmático, a educação de qualidade se resume ao

\footnotetext{
${ }^{5}$ Para os autores Baudelot e Establet (1971) a escola não difere do sistema capitalista, pois a classe dominante faz com que a mesma continue a reproduzir seus interesses. Ainda que a escola tenha as duas classes sociais presentes em seu espaço, onde deveria ofertar ensino igualitário, a segregação permanece em uma escolarização especifica para burguesia e proletariado. Nas duas esferas sociais a ideologia predominante continua sendo a burguesa.
} 
provimento de padrões aceitáveis de aprendizagem para inserir o indivíduo - como produtor-consumidor - na dinâmica do mercado (FONSECA, 2009, p. 154).

Consideramos que para haver qualidade é necessário que as politicas públicas assegurem tanto os componentes extras e intraescolares. Para que o aluno permaneça e alcance um melhor desempenho, é preciso que seja ofertado meios que atendam as exigências de aprendizagem. A educação de qualidade deve servir para melhorar a vida dos indivíduos. Os investimentos na educação devem ser antecipados por reflexões de como tal recurso será utilizado para benefício da população e como isso contribuirá para sua permanência e sucesso na trajetória escolar. Desta forma, devemos considerar que além do problema da dualidade do Ensino Médio e a busca pela qualidade social, há ainda necessidade de sua universalização que recai novamente sob um recorte de classe com consequências principalmente sobre a educação pública.

\section{ENSINO MÉDIO NO BRASIL E NO AMAPÁ: DISCREPÂNCIAS, APRO- XIMAÇÕES E A QUALIDADE DO ENSINO}

Diante da análise do conceito de Politecnia ${ }^{6}$, passamos analisar uma alternativa pedagógica de Ensino Médio para os jovens da região amazônica. Os jovens, de uma forma geral, deveriam estar em uma escola média politécnica com uma formação ampla, incluindo a profissional; no entanto, como a realidade da classe trabalhadora é distinta, precária, e "desvalida de fortuna" (FRIGOTTO, 2009, p.8), os jovens adentram precocemente ao mundo do trabalho fragilizando suas possibilidades.

Para a pedagogia marxista, os adolescentes não são individualidades metafísicas ou naturalmente determinadas, fechadas em si mesmas e engessadas em sua classe social, à guisa de castas. Ajudá-los a descobrir, aos poucos, por meio de repetidos ensaios, sua identidade profunda, é tarefa da formação escolar média, oferecendo uma formação omnilateral. Mas, cuidado: formação omnilateral ou integral não significa saber fazer um pouco de tudo ou conhecer os fundamentos científicos de todos ramos da tecnologia e sim saber

\footnotetext{
${ }^{6}$ Politecnia diz respeito ao domínio dos fundamentos científicos das diferentes técnicas que caracterizam o processo de trabalho produtivo moderno. Está relacionada aos fundamentos das diferentes modalidades de trabalho (SAVIANI, 2003).
} 
fazer com excelência algo em sintonia com o próprio talento e, ao mesmo tempo, poder usufruir de todos os bens produzidos pela civilização contemporânea. (NOSELLA, 2009, p. 18).

Evidenciamos baixos índices de desenvolvimento do Ensino Médio quando analisamos este nível de ensino por localidade, a partir das zonas rural e urbana. Observe a tabela abaixo:

TABELA 01 - BRASIL - Taxas de Rendimento das escolas Estaduais na zona Rural e Urbana no ano de 2015

\begin{tabular}{l|c|c|c|c|c|c}
\hline \multirow{2}{*}{ Anos } & \multicolumn{3}{|c|}{ Zona Rural } & \multicolumn{3}{c}{ Zona Urbana } \\
\cline { 2 - 7 } & $\mathbf{1}$ & $\mathbf{2}$ & $\mathbf{3}$ & $\mathbf{1}$ 年 & $\mathbf{2}$ & 3ㅇ \\
\hline Aprovação & $76,1 \%$ & $83,9 \%$ & $89,2 \%$ & $72,2 \%$ & $81,7 \%$ & $87,9 \%$ \\
\hline Reprovação & $12 \%$ & $7,4 \%$ & $4,1 \%$ & $18 \%$ & $11,1 \%$ & $6,7 \%$ \\
\hline Abandono & $11,9 \%$ & $8,7 \%$ & $6,7 \%$ & $9,8 \%$ & $7,2 \%$ & $5,4 \%$ \\
\hline
\end{tabular}

FONTE: Censo Escolar 2015, Inep.

Segundo os dados levantados pelo Inep no ano de 2015, o $1^{\circ}$ ano do ensino médio nas escolas estaduais brasileiras apresentaram $11,9 \%$ de abandono. Este percentual pode caracterizar fatores intrísecos ou extrínsecos à escola. O maior percentual se compararmos às duas séries deste nível de ensino. Pelas escolas das zonas rurais não estarem presentes em todas as localidades onde há população carente de ensino, a distância e a falta de transporte pode ser um dos fatores que contribuíram para este resultado, principalmente na região Amazônica, como o levantamento feito em um Projeto de Assentamentos (PAS) realizado no Pará com famílias do campo.

A merenda, quando chega, é de péssima qualidade, pela demora na distribuição da mesma, pela ausência de transporte ou vicinais intrafegáveis; inexistência de transporte escolar rural nos PAS. Crianças chegam a caminhar longas distâncias para chegar à escola, muitas vezes localizadas em outras comunidades que não a sua. (CANALI, 2007, p. 21).

Sob outro aspecto, referente à realidade ribeirinha da Amazônia, podemos evidenciar a partir de Silva e Martins (2019) que os problemas de gestão do transporte escolar, desdobram-se em problemas de uso, manutenção e acesso à informação. Esses problemas de gestão apresentaram impactos negativos tanto nos indicadores de abandono, reprovação e assiduidade dos alunos, quanto na qualidade do transporte fluvial, levando ao 
questionamento sobre as políticas de gestão das prefeituras para o transporte escolar. Portanto, a garantia do transporte escolar não é suficiente para garantir aos alunos usuários o acesso e a permanência nas mesmas.

Além da região Amazônica, podemos citar um estudo realizado no estado de Minas Gerais, que também aborda a questão da evasão do ensino médio público. Os autores Soares, Fernandes, Nóbrega e Nicolella elecanram como principais fatores a dificuldade nas disciplinas, ânsia por uma escola diferente, percepção de melhores oportunidades de trabalho com a continuidade dos estudos e a importância atribuída na escolha à escola. Fatores estes que são considerados intrísecos ou extrísecos à escola.

\footnotetext{
Fatores intrínsecos e extrínsecos à escola, como drogas, sucessivas reprovações, prostituição, falta de incentivo da família e da escola, necessidade de trabalhar, excesso de conteúdos escolar, alcoolismo, vandalismo, falta de formação de valores e preparo para o mundo do trabalho influenciam diretamente nas atitudes dos alunos que se afastam da escola. Esses obstáculos, considerados, na maioria das vezes, intransponíveis para milhares de jovens, engrossam 0 desemprego ou os contingentes de mão de obra barata. (ARAÚJO; FILHO, 2017, p. 39).
}

Deste modo ao partirmos da compreensão que a população brasileira na zona urbana é de $85 \%$ e da zona rural é de 15\% (IBGE, 2010), observamos que o Ensino Médio brasileiro vem passando por um processo de urbanização, o qual demonstra que as diferenças entre os percentuais de matrículas no Ensino Médio nas zonas urbana e rural são consideravelmente maiores que a diferença entre as populações das zonas urbana e rural residentes no Brasil.

Portanto, a escola pública é o único espaço que os filhos da classe trabalhadora possuem para viabilizar a sua relação com o conhecimento. A escola deve garantir as ferramentas para uma educação de qualidade, pois não basta estar matriculado em um nível de ensino e não ter as condições básicas de concluí-lo. O Ensino Médio Integrado deve haver uma possibilidade real de espaço para uma educação politécnica e democrática.

Sob essa perspectiva, um projeto pedagógico integrador, inclusive o projeto do ensino médio integrado, implica atitude politica que viabilize o ensino fundado no conhecimento cientifico em articulação com os saberes populares e tácitos e uma metodologia em que os ensinantes e aprendizes sejam sujeitos ativos do processo pedagógico. (ARAUJO, 2014). 
Diante do exposto, observamos que o Ensino Médio no Brasil possui indicadores educacionais preocupantes. A sua materialização na realidade de um país de capitalismo periférico dentro de uma região periférica (região norte), reflete um contexto marcado por problemas na sua qualidade, expressa nos indicadores educacionais de rendimento.

Abaixo a tabela com as taxas de rendimento nos municípios amapaenses nas suas zonas urbana e rural no ano de 2015:

TABELA 03 - Taxa de Aprovação do Ensino Médio no estado do Amapá no ano de 2015.

\begin{tabular}{l|c|c}
\hline \multicolumn{1}{c|}{ Município } & Zona Rural \% & Zona Urbana \% \\
\hline BRASIL & 83,0 & 80,6 \\
\hline AMAPÁ & 75.4 & 73,89 \\
\hline Macapá & 74,9 & 71,4 \\
\hline Amapá & -- & 76,2 \\
\hline Calçoene & 71,4 & 60,7 \\
\hline Cutias & 93,6 & 83 \\
\hline Ferreira Gomes & -- & 71,9 \\
\hline Itaubal & 67,3 & 93,4 \\
\hline Laranjal do Jari & 76,5 & 69,7 \\
\hline Mazagão & 78,5 & 60,1 \\
\hline Oiapoque & 93,5 & 70,4 \\
\hline Pedra Branca & 81,6 & 78,4 \\
\hline Porto Grande & 58,7 & 74,7 \\
\hline Pracuúba & 56,5 & 75,8 \\
\hline Santana & 73,3 & 80,8 \\
\hline Serra do Navio & 73,0 & 59,3 \\
\hline Tartarugalzinho & 77,7 & 76,5 \\
\hline Vitória do Jari & 79,5 & 80 \\
\hline
\end{tabular}

Fonte: INEP, 2015.

A princípio, destacamos que diversos municípios da região amazônica principalmente na sua zona rural, não apresentaram registros dos seus dados educacionais. Esta situação já foi encontrada em trabalho recente publicado por Alves, Araujo e Rodrigues (2015) os quais verificaram diversas lacunas no 
preenchimento de dados de fluxo no Ensino Médio em toda região amazônica, a qual torna-se recorrente entre municípios do estado do Amapá, como no caso dos municípios Ferreira Gomes e Amapá.

Os dados de aprovação na zona rural revelam-se positivos no ano de 2015 em relação à zona urbana, no entanto preocupantes em relação à realidade nacional. O município que apresentou maior taxa de aprovação foi Cutias com 93,6\%, seguido por Oiapoque com 93,5\% e Pedra Branca com $81,6 \%$. No geral, Cutias e Oiapoque (rural) e Itaubal (urbana) apresentaram as melhores taxas de aprovação no ensino médio. Os municípios que menos aprovaram foram: Pracuúba e Porto Grande (rural) e Serra do Navio (urbana).

Realizando uma leitura unilateral, com base nos dados apresentados, observamos que a maioria dos municípios amapaenses não apresentam índices preocupantes (salvo os municípios Calçoene - Rural, e Itaubal, Porto Grande e Pracuúba - Urbana) quando comparados à realidade nacional. No entanto, há outros aspectos analisados, sobre os quais fazemos algumas observações a seguir: o município de Itaubal apresenta a melhor taxa de aprovação do estado do Amapá, superando a capital Macapá e a média de aprovação na zona urbana de todo o estado, inclusive a média nacional. Todavia, a zona rural deste município apresenta um dos piores índices de aprovação.

Para tentar entender esta discrepância, observamos dados extraescolares sobre o município que nos revelam que Itaubal apresentou 0 pior IDHM do estado no ano de 2015 chegando a 0,576, abaixo dos melhores índices do estado, como na capital Macapá, que ficou em 0,733.

Cabe aqui questionarmos o fato que o município Itaubal apresentar altas taxas de aprovação na zona rural, mas apresentar o pior IDHM do estado, considerando que este índice reúne um conjunto de indicadores sociais, dentre os quais a educação. Possui também, o $7^{\circ}$ pior índice de pobreza (IPH) do estado. É importante relembrar que o Brasil encontra-se afetado pelas avaliações do IDEB, que incluem o número de aprovações, ou seja aprovar passa ser uma estratégia para melhoria dos índices, independentemente da qualidade do ensino e da aprendizagem do aluno. Na busca de combater a 
distorção aluno $X$ série, os alunos são aprovados sem condições de avançarem para as séries posteriores. É importante destacarmos que não defendemos a prática de reprovação, mas entendemos que quando o IDEB indica taxa de aprovação para melhorar os índices, leva a outro tipo de distorção: uma distorção relacionada a aluno $x$ série $x$ conhecimento. Pode haver uma alta taxa de aprovação influenciada pela tentativa de melhorar o IDEB. As práticas de "aprovação automática" em diferentes locais do Brasil, em especial no final do ensino fundamental, também podem interferir no desempenho no EM, e por consequência gerar reprovação e evasão.

Podemos ainda sugerir do ponto de vista pedagógico a gestão da política educacional do município de Itaubal (com extensão aos demais municípios do estado) apresenta problemas na articulação e planejamento educacional entre as zonas urbana e rural, e entre o município enquanto ente federado com a capital Macapá, resultado de distintas formas de realização e gestão do ensino médio entre o estado e os municípios.

Além de Itaubal, os municípios Porto Grande, Cutias, Pedra Branca, Vitória, Pracuúba, Mazagão, Tartarugalzinho apresentam IDHM consideravelmente baixo, ou seja, pelo menos $85 \%$ dos municípios amapaenses estão com IDHM considerado Médio ou Baixo, conforme tabela abaixo:

Tabela 03 - Índices de Desenvolvimento Social/Humano nos Municípios do Amapá em 2015.

\begin{tabular}{|c|c|c|c|c|c|}
\hline MUNICÍPIO & IDHM & $\begin{array}{c}\text { POBREZA } \\
\%\end{array}$ & $\begin{array}{l}\text { INDICE } \\
\text { DE GINI }\end{array}$ & ECONOMIA & $\begin{array}{l}\text { ÍNDICES EM } \\
\text { DESTAQUE }\end{array}$ \\
\hline MACAPÁ & 0,733 & 36,41 & 0,45 & SERVIÇOS & REPROVAÇÃO \\
\hline $\begin{array}{l}\text { SERRA DO } \\
\text { NAVIO }\end{array}$ & 0,709 & 27,84 & 0,38 & SERVIÇOS & REPROVAÇÃO \\
\hline SANTANA & 0,692 & 43,11 & 0,43 & SERVIÇOS & REPROVAÇÃO \\
\hline LARANJAL & 0,665 & 46,2 & 0,38 & SERVIÇOS & ABANDONO \\
\hline OIAPOQUE & 0,658 & 53,88 & 0,41 & SERVIÇOS & ABANDONO \\
\hline FERREIRA & 0,656 & 37,63 & 0,33 & INDUSTRIA & ABANDONO \\
\hline CALÇOENE & 0,643 & 49,67 & 0,4 & SERVIÇOS & REPROVAÇÃO \\
\hline AMAPÁ & 0,642 & 48,46 & 0,4 & SERVIÇOS & ABANDONO \\
\hline PORTO GRANDE & 0,64 & 33,64 & 0,4 & SERVIÇOS & ABANDONO \\
\hline CUTIAS & 0,628 & 47,32 & 0,32 & AGROPECUÁRI & APROVAÇÃO \\
\hline
\end{tabular}




\begin{tabular}{|c|c|c|c|c|c|}
\hline & & & & A & \\
\hline PEDRA BRANCA & 0,626 & 37,46 & 0,43 & INDÚSTRIA & APROVAÇÃO \\
\hline VITÓRIA & 0,619 & 49,82 & 0,38 & SERVIÇOS & APROVAÇÃO \\
\hline PRACUÚBA & 0,614 & 73,69 & 0,33 & $\begin{array}{c}\text { AGROPECUÁRI } \\
\text { A }\end{array}$ & REPROVAÇÃO \\
\hline MAZAGÃO & 0,592 & 40,52 & 0,41 & SERVIÇOS & REPROVAÇÃO \\
\hline TARTARUGAL & 0,592 & 45,45 & 0,39 & $\begin{array}{c}\text { AGROPECUÁRI } \\
\text { A }\end{array}$ & APROVAÇÃO \\
\hline ITAUBAL & 0,576 & 45,46 & 0,3 & $\begin{array}{c}\text { AGROPECUÁRI } \\
\text { A }\end{array}$ & ABANDONO \\
\hline
\end{tabular}

FONTE: IBGE; INEP 2014, 2015. Legenda- IDHM: Muito Alto, de 0,800 a 1000 (nenhum município); Alto, de 0,700 a 0,799 (2 municípios); Médio, de 0,600 a 0,699 (11

municípios); Baixo, de 0,500 a 0,599 (3 municípios); Muito Baixo, de 0,000 a 0,499.

Esta constatação referente ao IDHM médio e baixo dos municípios amapaense é fundamental para compreendermos a qualidade social do Ensino Médio no estado do Amapá. Dourado e Oliveira (2009) reafirmam que "é fundamental ressaltar que a educação se articula a diferentes dimensões e espaços da vida social sendo, ela própria, elemento constitutivo e constituinte das relações sociais mais amplas".

Sobre os elementos constitutivos da vida em sociedade observamos que o município de Pracuúba apresenta a pior taxa de pobreza do estado, indicando que há problemas neste município relacionados ao alto número de adultos analfabetos, baixas taxas de longevidade, e problemas relacionados à saúde humana, incluindo desnutrição de crianças. Outra constatação relevante é que a capital Macapá e o segundo maior município do estado, Santana, concentram os dois piores índices de Gini, ou seja, os dois maiores centros urbanos do estado apresentam os maiores índices de desigualdade, considerando assim que uma pequena parcela da população detém a maior parte dos recursos produzidos no estado.

Observamos abaixo as taxas de reprovação do Ensino Médio no estado do Amapá no ano de 2015: 
TABELA 04 - Taxa de Reprovação do Ensino Médio no estado do Amapá no ano de 2015.

\begin{tabular}{l|c|c}
\hline \multicolumn{1}{c|}{ Município } & $\begin{array}{c}\text { Zona Rural } \\
\%\end{array}$ & Zona Urbana \% \\
\hline BRASIL & 7,8 & 11,9 \\
\hline AMAPÁ & 8,0 & 13,1 \\
\hline Amapá & -- & 7,0 \\
\hline Calçoene & 10,5 & 21,5 \\
\hline Cutias & 0,0 & 2,3 \\
\hline Ferreira Gomes & -- & 6,6 \\
\hline Itaubal & 8,0 & 2,9 \\
\hline Laranjal do Jari & 0,0 & 16,3 \\
\hline Macapá & 11,9 & 16,8 \\
\hline Mazagão & 8,3 & 22,0 \\
\hline Oiapoque & 0,0 & 17,9 \\
\hline Pedra Branca & 1,7 & 17,8 \\
\hline Porto Grande & 13,2 & 17,0 \\
\hline Pracuúba & 13,0 & 0,0 \\
\hline Santana & 10,7 & 11,8 \\
\hline Serra do Navio & 5,6 & 25,3 \\
\hline Tartarugalzinho & 2,9 & 11,3 \\
\hline Vitória do Jari & 2,3 & 1,4 \\
\hline FONTE: INEP 2015 & &
\end{tabular}

Os piores índices de reprovação continuam mais evidentes na zona urbana. O município que apresentou maior taxa de reprovação foi Serra do Navio com 25,3\%. O segundo município com índice elevado de reprovação na zona urbana foi Mazagão com 22\%. Calçoene foi o terceiro município com taxa de reprovação considerável, com $21,5 \%$. Os municípios que menos reprovaram foram: Pracuúba $(0 \%)$, Vitória $(1,4 \%)$ e Cutias $(2,3 \%)$.

Neste caso, trazemos novamente o dilema marcado pela qualidade do ensino médio na cidade e no campo, o qual apresenta a zona rural se sobressaindo positivamente. Novamente trazemos a tona a diferenciação do Ensino Médio Modular em relação Ensino Médio Regular como elementos que contribuem para estas distinções entre as zonas urbana e rural. 
Em outra circunstância, destacamos novamente que as taxas na margem $0 \%$, pouco ou em nada contribuem para o esclarecimento da problemática reprovação no Ensino Médio, pois compreendemos que as taxas desta natureza podem nos sugerir equívocos no seu registro.

Outro elemento que pode contribuir para evidenciar as discrepâncias sociais/educacionais verificadas nos índices sociais e de fluxo no Ensino Médio do estado do Amapá refere-se à atividade econômica desenvolvida em cada município. Observamos neste caso que aqueles que apresentam atividade econômica pouco desenvolvida como por exemplo a agropecuária (vide tabela 03), apresentam índices sociais/educacionais ainda mais preocupantes (a exemplo Itaubal, Pracuúba, Tartarugal e Cutias).

Diante destas análises prévias, observamos abaixo as taxa de abandono do Ensino Médio no estado do Amapá:

TABELA 5 - Taxa de Abandono do Ensino Médio no estado do Amapá no ano de 2015.

\begin{tabular}{l|c|c}
\hline \multicolumn{1}{c|}{ Município } & $\begin{array}{c}\text { Zona Rural } \\
\%\end{array}$ & Zona Urbana \% \\
\hline BRASIL & 9,1 & 7,4 \\
\hline AMAPÁ & 18,2 & 13,7 \\
\hline Amapá & -- & 16,8 \\
\hline Calçoene & 18,1 & 17,8 \\
\hline Cutias & 6,4 & 14,7 \\
\hline Ferreira Gomes & -- & 21,5 \\
\hline Itaubal & 24,7 & 3,7 \\
\hline Laranjal do Jari & 23,5 & 14,0 \\
\hline Macapá & 13,3 & 11,8 \\
\hline Mazagão & 13,2 & 17,9 \\
\hline Oiapoque & 6,5 & 11,7 \\
\hline Pedra Branca & 16,7 & 3,8 \\
\hline Porto Grande & 28,1 & 8,3 \\
\hline Pracuúba & 30,5 & 24,2 \\
\hline Santana & 16,0 & 7,4 \\
\hline Serra do Navio & 21,4 & 15,4 \\
\hline Tartarugalzinho & 19,4 & 12,2 \\
\hline Vitória do Jari & 18,2 & 18,6 \\
\hline
\end{tabular}


Os dados sobre abandono foram maiores na zona rural no ano de 2015 . O município que apresentou maior taxa de abandono foi Pracuúba com 30,5\%. O segundo município com índice elevado de abandono na zona urbana foi Porto Grande com 28,1\%. Itaubal foi o terceiro município com taxa de abandono considerável com $24,7 \%$. Os municípios do Amapá com as menores taxas de abandono foram: Cutias $(6,4)$, Oiapoque $(6,5)$ e Mazagão $(13,2)$.

De uma forma geral alguns dados nos chamam atenção: por exemplo, os municípios de Oiapoque, Laranjal do Jari e Cutias foram os que apresentaram os melhores índices educacionais em relação ao Ensino Médio. Trata-se de municípios com índices de desenvolvimento humano apenas discretos em relação à média estadual, ocupando respectivamente o quarto, quinto e décimo índices do estado. Além disso, suas médias apresentaram índice $0 \%$ de aprovação, reprovação ou abandono. Diante destas considerações, no geral, os maiores municípios do estado (Macapá e Santana) acabam apresentando os melhores índices. Sugerimos que este fato tem como base o fato de apresentarem um Ensino Médio de forma mais linear e menos acidentada em relação aos demais municípios, e ainda por centralizarem as ações pedagógicas e o desenvolvimento econômico do estado.

Observamos que os dados que mais oscilaram, se for comparada as duas localidades, foram os municípios Ferreira Gomes, Itaubal, Macapá, Pracuúba, Santana, Serra do Navio e Vitória do Jari. Esta situação é prolongada na relação geral entre os dados, no qual cabem destaque à capital Macapá e a segunda maior cidade do estado Santana, que registram índices gerais preocupantes no que se refere a dados negativos por um lado como na reprovação de $16,8 \%$ na capital Macapá na zona urbana, e a taxa de abandono de $16 \%$ na zona urbana do município de Santana, e por outro lado apresentaram dados positivos como Santana que apresenta taxa de aprovação de $80,8 \%$, superior a média nacional, e Macapá apresentando 11,8\% como taxa de abandono.

A literatura nos ensina que o Ensino Médio possui diversas lacunas e problemas a serem resolvidos que parte do acesso, visto que há poucas vagas 
no sistema público, além da identidade local, pois se ressente com a falta de uma escola que contemple as realidades vivenciadas pelos indivíduos; além da qualidade social, com um ensino que proporcione condições necessárias de integração dos conhecimentos e com real sentido em suas vidas.

Finalmente, os segmentos da sociedade que veem positivamente 0 ensino médio integrado à educação profissional tendem a coincidir com aqueles que dependem da oferta pública da educação básica. Diante da baixa qualidade da oferta, a educação profissional não deixa de ser uma alternativa de funcionalidade do ensino, no sentido de proporcionar uma suposta facilidade de ingresso no mercado de trabalho. (CIAVATTA, RAMOS, 2011, p.35)

Já os dados relacionados ao IDHM apresentam Macapá e Santana entre os maiores do estado, ao lado Serra do Navio, Laranjal, Oiapoque, Ferreira Gomes e Amapá. Sendo que Amapá e Laranjal apresentam elevados índices de Abandono. No geral, não identificamos uma confirmação entre os dados educacionais e os índices de desenvolvimento humano nos municípios amapaenses.

Seguindo esta análise, na tabela 3 percebemos que Macapá tem o melhor IDHM, detém mais de $30 \%$ de sua população em situação de Pobreza, porém os dados levantados mostraram que a Reprovação é mais evidente que as demais taxas de rendimento. Neste caso observamos que os indicadores socioeconômicos não mudaram ou interferiram neste índice negativo. Serra do Navio tem o segundo melhor IDHM, possui $9 \%$ menos situação de Pobreza do que a capital Macapá, assim como seu índice de GINI com 7\% a menos. Mas os índices de Reprovação também caracterizam este município. Já o município de Santana com o terceiro maior IDHM tem mais $40 \%$ de população pobre. A Reprovação também apresenta maior índice. Laranjal apresenta mais de $50 \%$ de sua população em situação de pobreza, este dado pode está relacionado com a taxa elevada de Abandono, levando os jovens a buscarem condições de trabalho para a subsistência de suas famílias e consequentemente a desistência da trajetória escolar.

Como forma de melhor contextualização, a economia do estado do Amapá os dois ramos que mais se destacam são Indústria e Serviços, ou seja, extração de minérios e comércio. Percebemos que o município de Pedra 
Branca, onde há a exportação de mineral, obteve índices satisfatórios, tanto na zona urbana quanto na rural, maior aprovação e menor reprovação e abandono.

Verificamos ainda, que a infraestrutura deste município colabora com esses resultados, com o índice de pobreza de 37,46\%, IDHM de 0,626 e seu índice de gini de 0,43. E para contrastar com Pedra Branca, o município de Pracuúba está presente nos piores índices. Talvez por ter sua economia concentrada na agricultura, ramo que não é tão desenvolvido no estado. A hipótese que se levanta é que há baixíssimos recursos que atendem este município, e os jovens, de uma forma geral, abandonam a escola para trabalhar precocemente.

Cabe aqui destacar, que não se trata de municípios em evidência, estruturados, com melhores IDHs do estado, ou com melhores oportunidades que são os detentores dos melhores índices. O Amapá não está entre os estados com melhores resultados, afinal metade dos alunos está fora da trajetória escolar e cerca de $40 \%$ a $50 \%$ de sua população vive em situação de pobreza.

Entre os anos de 2005 a 2015 o IDEB do Amapá, aumentou de 2,69 para 3,07 o que não necessariamente representou avanços significativos na qualidade de sua educação. Segundo o Censo escolar do ano de 2015, a maioria das escolas deste estado oferece o ensino médio regular no turno noturno com $76,2 \%$ e $3,9 \%$ são escolas que oferecem 0 ensino profissionalizante (BRASIL, 2015).

Os dados e cenários apresentados nos revelam a exclusão educacional/social na Amazônia e sua faceta no estado do Amapá tem atingido a qualidade da educação e a formação dos sujeitos. Temos portanto, que para uma educação integrada aos jovens se o acesso já é dificultado, a qualidade do ensino médio no Amapá torna-se um desafio complexo.

(...) as dificuldades que têm pautado os processos de construção de uma proposta de qualidade para o ensino médio integrado, na perspectiva dos que vivem do trabalho, não podem ser resolvidas por soluções pedagógicas, uma vez que a ruptura entre o geral e o profissional, entre o trabalho intelectual e a atividade prática, está na 
raiz da constituição do modo de produção capitalista. (KUENZER, 2010, p.863).

Nosella (2009) adverte que é necessária a garantia de acesso e permanência aos educandos, já que estão saindo do ensino básico para adentrar ao superior, entretanto, por inexistência de recursos para a infraestrutura, materiais didáticos, condições salariais dos educadores, 0 ensino fica cada vez mais desgastado e desvalorizado. Desta forma os alunos não idealizam melhorias permanecendo em sua trajetória escolar, escolhendo o mercado de trabalho e sua condição pautada no imediato para alcançar uma profissão mais estável, no entanto, sem garantias de qualidade.

\section{CONCLUSÃO}

A forma de realização do Ensino Médio no Amapá se materializa de forma dual sob a marca da divisão social do trabalho: por um lado destacado por uma formação ampla e contempladora das necessidades humanas, mas por outro, sob a marca das insuficiências pedagógicas, sociais e humanas.

O Ensino Médio no Amapá, segundo os dados levantados, apresentou índices negativos em relação à zona urbana, pois as taxas de Reprovação e Aprovação foram elevadas. Sendo assim, as clássicas afirmações que os piores índices educacionais concentram-se nas escolas da zona rural (pela maior estrutura e serviços prestados nos centros urbanos) foi "parcialmente" desfeita a partir da análise descontextualizada dos dados; no entanto, foi contraditoriamente confirmada quando os diversos dados foram intercruzados e contextualizados entre si, por algumas bases e levantamentos apresentaremse frágeis e duvidosos.

Neste mesmo sentido, os municípios com melhores dados foram àqueles distantes da capital e que possuíam poucas escolas que ofertavam o nível de ensino em questão, contraditoriamente, os dados relativos a vida social dos alunos revelavam uma inserção sob uma realidade marcada pela pobreza e pela desigualdade social. As discrepâncias ainda foram mais dramáticas quando comparadas a realidade nacional, o que implica dizer que $o$ aluno abandona a escola no ensino médio pela mesma não corresponder suas 
expectativas sejam de caráter formativo, seja pela necessidade de adaptação a uma realidade distinta. Digamos, que uma compreensão mais linear obteve-se mediante as taxas de abandono na zona rural que constantemente revelaramse elevadas.

Portanto, a construção da qualidade social necessita da construção de um ambiente politico, econômico, cultural que permita à escola ser agente estratégico de melhoria de vida a todos os envolvidos com ela. A qualidade social na educação é alcançada quando a vida de toda a comunidade escolar e da comunidade ao seu redor estiver sendo melhorada.

Diante de nossas reflexões podemos sugerir que os sujeitos buscam a capital Macapá e os principais centros urbanos do estado em busca de melhores condições sociais e que implicam na sua necessidade de subsistência. No entanto, a desigualdade social se manifesta nos níveis de pobreza, analfabetismo, longevidade, saúde, entre outros, constituindo referências importantes para afirmar que o capital impõe uma educação para a periferia da Amazônia sob as delimitações da divisão social do trabalho e de uma educação pública com formação unilateral e insuficiente para 0 atendimento das demandas de desenvolvimento do estado.

Portanto, ainda que haja resistências da sociedade amapaense no contexto do Ensino Médio, mais importa uma trajetória escolar para a composição de estatísticas e índices de "desenvolvimento" educacionais que na realidade significa a reprodução das funções de mão de obra nos limitados setores da economia do estado (serviços, agricultura, indústria), que uma formação humana ampliada dos sujeitos alicerçada pelas organizações populares para o desenvolvimento da autonomia, liderança e criticidade dos sujeitos.

Durante nossos estudos sobre o Ensino Médio no Amapá, acompahamos a lei no 13.415/2017 que reformou este nível de ensino. Trata-se de uma reforma que abre possibilidades para novas pesquisas, mas como pistas observamos que ela aprofunda os "velhos" problemas do Ensino Médio brasileiro, pautados pela dualidade e desigualdade educacional. Além do mais esta reforma reforça a condição de classe deste nível de ensino, aligeirando a 
formação dos "desafortunados" e submetendo-os a uma inserção desqualificada no mercado de trabalho, em detrimento do desenvolvimento de estudos superiores.

De uma forma geral, a reforma do "novo ensino médio assinala 0 aprofundamento do abismo entre a educação da população brasileira pobre, e das classes favorecidas. Mais dramático ainda seria projetarmos os impactos da reforma deste nível de ensino para os estados brasileiros desinvestidos pelo capital financeiro, e com baixos índices de industrialização, tal qual boa parte da região amazônica e particularmente o estado do Amapá.

\section{REFERÊNCIAS}

ALVES, J. P. C.; ARAUJO, R. M. L.; RODRIGUES, D. S. Indicadores educacionais e a ideia da integração do ensino: o ensino médio na Amazônia sob análise. Novos Cadernos NAEA, v. 18 n. 3, p. 231-260, jun.-set. 2015.

AGÊNCIA PÚBLICA. Um orgulho raro (Fabiano Angélico). Disponível em http://apublica.org/2012/07/serie-futuro-da-amazonia-parte-1/. Acesso em 02 de novembro de 2016.

Corrupção e educação na Amazônia. Disponível em http://apublica.org/2012/07/corrupcao-e-educacao-na-amazonia-2/. Acesso em 02 de novembro de 2016.

ARAUjO, R. M. L. Práticas Pedagógicas e Ensino Integrado. Coleção Formação Pedagógica, v. 7, 2014.

ARAUJO, R. M. L.; RODRIGUES, D. S. Filosofia da Práxis e Ensino Integrado: para além da questão curricular. Revista do NETE, Belo Horizonte, 2010.

ARAÚJO, R. M. L; SILVA FILHO, R. B. Evasão e abandono escolar na educação básica no Brasil: fatores, causas e possíveis consequências. Educação Por Escrito, Porto Alegre, v. 8, n. 1, p. 35-48, jan.-jun. 2017.

ARAÚJO, M. N. C.; CANALI, H. H. B.; RODRIGUES, D. S.; SILVA, G. P. Educação do Campo na Amazônia: uma experiência. Disponível em www.campuscameta.ufpa.br/images/textos/educacaocampo_amazonia.pdf. Acesso em 23 de agosto de 2019.

BRASIL. Censo da educação básica 2012: resumo técnico. Brasília: INEP, 2015. 
CIAVATTA, M.; RAMOS, M. Ensino Médio e Educação Profissional no Brasil: dualidade e fragmentação. Revista Esforce, v. 5, n. 8, 2011.

DOURADO, L. F.; OLIVEIRA, J. F. A qualidade da educação: perspectivas e desafios. São Paulo: brasiliense, 2009.

FERNANDES, Neimar da Silva.; NICOLELLA, Alexandre Chibibe.; NÓBREGA, Mariana Calife.; SOARES, Tufi Machado. Fatores associados ao abandono escolar no ensino médio público de Minas Gerais. Educação e Pesquisa, São Paulo, v. 41, n. 3, p. 757-772, jul./set. 2015.

FONSECA, Marília. Políticas Públicas para a Qualidade da Educação brasileira: entre o utilitarismo econômico e a responsabilidade social. Cadernos Cedes, Campinas, v. 29, 2009.

FRIGOTTO, Gaudêncio; CIAVATTA, Maria; RAMOS, Marise. Ensino médio integrado: concepção e contradições. São Paulo: Cortez, 2005.

FRIGOTTO, Gaudêncio. Juventude, trabalho e educação no Brasil: perplexidades, desafios e perspectivas. In: NOVAES, Regina; VANNUCHI, Paulo et al. Juventude e sociedade: trabalho, educação, cultura e participação. São Paulo: Fundação Perseu Abramo, 2009.

FRIGOTTO, Gaudêncio; MOTTA, Vânia Cardoso da. Por que a urgência da reforma do ensino médio? Medida provisória no 746/2016 (LEI № 13.415/2017). Educação e Sociedade, Campinas, v. 38, n. 139, p.355-372, abr.-jun., 2017

GADOTTI, Moacir. Qualidade na Educação: uma nova abordagem. Florianópolis: Congresso de Educação Básica, 2013.

KUENZER, A. Z. O Ensino Médio agora é para a vida: entre o pretendido, o dito e o feito. Educação e Sociedade, campinas, v. 21, n. 70, p.15-39, 2000.

. O ensino médio no plano nacional de educação 2011-2020: superando a década perdida? Educação e Sociedade, Campinas, v. 31, n. 112, p. 851873, 2010.

MINAYO, M. C. S; SANCHES, O. Quantitativo-Qualitativo: oposição ou complementaridade? Cadernos de Saúde Pública, Rio de Janeiro, v. 9, n. 3, 239-262, jul/set, 1993.

NOSELLA, Paolo. Ensino Médio: em busca do princípio pedagógico. São Paulo: VI Colóquio de Pesquisa sobre Instituições Escolares, 2009.

SANTOS, T. F. A. M. dos. A Educação no desenvolvimento da Amazônia. Congresso Íbero-Americano da Associação de Política e Administração Educacional. Goiânia (Go), 2016. Disponível em 
www.anpae.org.br/IBERO...IV/GT5/.../TerezinhaFatimaSantos_GT5. Acesso em 02 de novembro de 2016.

SILVA, Luciane Teixeira da; MARTINS, Egídio. A qualidade do transporte escolar realizado por lanchas na Amazônia a partir das análises dos sujeitos envolvidos. In: SILVEIRA, Éderson Luís \& SANTANA, Wilder Kleber Fernandes de. (Orgs). Educação: ressonâncias teóricas e práticas. São Carlos: Pedro \& João Editores, 2019. 368p. (vol. 1)

Recebido em: 01/05/2019

Aprovado em: 01/10/2019 